\title{
VIOLÊNCIA E DISCURSO POLÍ- TICO EM A RODA DO MUNDO DA CIA DOS COMUNS
}

Resumo

$>$

Nesse artigo eu analiso a relação entre discurso e violência no teatro negro a partir do espetáculo $A$ roda do mundo, da Cia dos Comuns. Eu argumento que ao reivindicar a palavra, a Cia dos Comuns confronta um dos principais aspectos relacionados à persistente objetificação e desumanização do corpo negro: a negação do reconhecimento do corpo negro como um corpo capaz de ter e exercer uma perspectiva própria sobre si mesmo e sobre o mundo.

Palavras-chave:

Teatro negro. Violência. Corpo negro. 


\title{
VIOLÊNCIA E DISCURSO POLÍTICO EM A RODA DO MUNDO DA CIA DOS COMUNS
}

\author{
Gustavo Melo Cerqueira'
}

\footnotetext{
${ }^{1} \mathrm{PhD}$ em African and African Diaspora Studies pela Universidade do Texas em Austin, Estados Unidos. Professor substituto pelo Departamento de Técnicas do Espetáculo da Escola de Teatro da Universidade Federal da Bahia. ORDID: https://orcid. org/0000-0001-6247-1236. Email: melocerqueira111@ gmail.com
}

\section{Introdução}

Nesse artigo, eu proponho uma análise crítica sobre articulação de discurso e violência no teatro negro a partir do espetáculo $A$ roda do mundo, da Cia dos Comuns, grupo de teatro negro fundado pelo ator, diretor e agitador cultural Hilton Cobra em 2001, no Rio de Janeiro. Tomando como ponto de partida o que argumenta Leda Maria Martins, para quem uma das características principais do teatro negro é a reconfiguração da posicionalidade negra no teatro, movendo-o e deslocando-o da situação de objeto enunciado para a de sujeito produtor de discurso (MARTINS, 1995, p. 87), eu analiso como, em $A$ roda do mundo (MEIRELLES et al., 2001) a reivindicação da palavra para articulação de um discurso político que tanto reflita a experiência vivida negra quanto se oponha às estruturas políticas, sociais e ideológicas que persistentemente sujeitam negros e negras a diversas formas de violência gratuita, confronta um dos principais aspectos relacionados à persistente objetificação e desumanização do corpo negro: a negação do reconhecimento 
do corpo negro como um corpo capaz de ter e exercer uma perspectiva própria sobre si mesmo e sobre o mundo que o cerca (GORDON, 1999).

Ao eleger o corpo negro como aspecto fundamental para os argumentos que trago nesse artigo, é importante pontuar que abordo o corpo negro a partir de um modelo fenomenológico-existencialista proposto pelo filósofo estadunidense Lewis Gordon (1999) a partir de seu engajamento com a obra filosófica de Jean-Paul Sartre (1956). De acordo com esse modelo, o corpo é composto por três dimensões ontológicas: a primeira se refere ao corpo enquanto "consciência na carne ou consciência contextualizada"2 (GORDON, 1999, p. 34), isto é, consciência com uma perspectiva situada; a segunda dimensão ontológica do corpo se refere ao fato de o corpo ser visto por outros corpos uma vez que "o corpo nunca é um corpo em si mesmo, mas um corpo vivendo, um corpo agindo coisas e outros corpos"3 (1999, p. 35); e a terceira dimensão se refere à "habilidade de imaginar a perspectiva de outros"4 $(1999$, p. 36), ou seja, o corpo pode imaginar como é visto da perspectiva de um outro corpo. A partir dessa definição do corpo, Gordon opta por uma oposição binária entre corpo negro e corpo branco, uma vez que eles são mutuamente constitutivos dentro de uma abordagem fenomenológico-existencialista. Nessa abordagem, o que diferencia um corpo negro de um corpo branco é que enquanto o corpo branco é caracterizado principalmente por uma ênfase em sua primeira dimensão ontológica - ter uma perspectiva - o corpo negro é caracterizado principalmente pela ênfase em sua segunda dimensão ontológica - ser um objeto visto pela perspectiva de um outro corpo (GORDON, 1999, p. 102).

Ainda que não seja explicitamente apontado por Gordon em sua análise, é importante dizer que tal diferenciação em relação à ênfase colocada na primeira dimensão ontológica, no caso do corpo branco, e na segunda dimensão ontológica, no caso do corpo negro, são construídas através da história pelo emprego de formas diversas de violência tanto simbólica quanto material, especialmente durante os períodos de colonização e escravidão, que são aspectos estruturantes da maioria das sociedades ocidentais. Nesse sentido, as ênfases nas diferentes dimensões ontológicas em corpos brancos e negros são construções ideológicas que têm condicionado a existência e as relações de poder principalmente entre corpos brancos e corpos negros em sociedades antinegras, como é o caso da sociedade brasileira. De acordo com Gordon, em sociedades antinegras o corpo branco se impõe como norma e completa perspectiva, enquanto o corpo negro é representado como máximo desvio e falta de perspectiva (1999, p. 98-100).

Por conta das implicações de ordem política trazidas pela constituição e exercício de uma perspectiva própria no espetáculo $A$ roda do mundo da Cia dos Comuns, nesse artigo eu me proponho a abordar a ideia de negritude entendida aqui como a condição de ser negro ou negra - em proximidade com o entendimento proposto Saidiya Hartman (1997), que vê negritude como "relacionalidade social, mais do que identidade"5 (HARTMAN 1997, p. 56), o que complica a centralidade da negritude enquanto identidade racial conforme proposta em parte relevante da literatura acadêmica sobre o teatro negro. Por exemplo, Leda Maria Martins argumenta que "a reflexão sobre a identidade racial e sua problematização é veiculada tanto no texto representado quanto no texto ensaístico, compondo um leitmotiv em toda a prática teatral negra" (1995, p. 143). Julio Moracen Naranjo, por sua vez, caracteriza o teatro negro como um teatro que enfatiza a "identidade cultural do homem negro" (NARANJO, 2004, p. 121), sendo - portanto - um "teatro de identidade" (2004, p. 143). Evani Tavares Lima posiciona a identida-

\footnotetext{
2 "consciousness in the flesh or consciousness contextualized" (GORDON 1999, p. 34) Nota: todas as traduções do inglês para o português, nesse artigo, são minhas.

3 "the body is never a body by itself but a body living, a body acting amid things and other bodies" (GORDON, 1999, p. 35).

4 "the ability to imagine the perspective of others", (GORDON, 1999, p. 36).

${ }^{5}$ social relationality, rather than identity (HARTMAN, 1997, p. 56).
} 
de negra como "a base fundamental" do teatro negro (LIMA 2010, p. 1). Sem desmerecer a relevância dessas abordagens, e sobretudo por considerar que a negritude, enquanto identidade, é sempre um processo dialético de "ser e se tornar” (WRIGHT, 2004), eu considero válido pensar a ideia de negritude com maior ênfase na relacionalidade social de modo a fazer mais evidente sua faceta enquanto um construto e, ao mesmo tempo, fazer mais palpáveis suas implicações sociais, políticas e estéticas. Enquanto relacionalidade social, Hartman argumenta que a noção de negritude

incorpora sujeitos normativamente definidos como negros, suas relações entre negros, brancos e outros, e as práticas que produzem diferença racial. Negritude marca uma relação social de dominância e abjeção e, potencialmente, uma relação de reparação e emancipação ${ }^{6}$ (1997, p. 56-57)

Dessa forma, muito embora centrada em negros e negras, a ideia de negritude se torna, menos uma questão de quem eu sou e se torna mais relacionada a quem eu sou em relação a certos corpos, circunstâncias, situações e condições. Brandi Wilkins Catanese evoca a dimensão externa e performática da raça como uma maneira de auxiliar no entendimento da

categorização racial do self e do outro como a enunciação de uma espécie de contrato social, um convite para ou uma provocação de uma série de comportamentos e expectativas que garantem a alguém acesso à sociedade como um membro de um grupo privilegiado ou problematizado. ${ }^{7}$ (CATANESE, 2011, p. 19)

Nesse sentido, a designação racial reflete uma forma de designação vinda de fora que influencia profundamente como alguém participa numa sociedade e, ao mesmo tempo, como essa sociedade se organiza. Nesse sentido, a nega- ção da perspectiva de corpos que são definidos como negros não carrega uma mera diferenciação, mas envolve uma hierarquização de como a própria condição de humanidade é reconhecida ou negada em diferentes corpos (GORDON, 1999, p. 100). Esse processo de hierarquização tem um papel fundamental em garantir, via processo de contradistinção, que a perspectiva de um certo grupo racial se torne a norma, transformando certos corpos em donos da palavra (WYNTER, 1999), enquanto outros corpos são excluídos do domínio da fala (DEUS, 2009).

\section{Do discurso violento}

A exclusão do corpo negro do domínio da fala tem relação direta com a resistência em se reconhecer a perspectiva em corpos negros, com consequências diretas em como alguém é reconhecido ou não enquanto sujeito, o que também influencia a organização de uma dada sociedade ao determinar quem está habilitado ou não à participação política. Nesse sentido, reconstituir a palavra e o discurso produzido a partir da perspectiva do corpo negro é potencialmente situar negros e negras como sujeitos, e não como objetos. Como argumenta Gordon, a primeira dimensão ontológica do corpo pode ser chamada de consciência encorpada, cuja asserção por aqueles que têm sua perspectiva subjugada presume um engajamento com a política (GORDON, 2008). Ainda de acordo com Gordon, "os fenômenos políticos são governados pela oposição discursiva"8 (2008, p. 87). Assim, a exclusão de negros e negras do domínio da palavra significa, basicamente, impor-lhes a morte política. Nos termos sugeridos por Fred Moten,

A vida negra é vivida em morte política o é vivida, se preferir, no cemitério do sujeito por aqueles que, na medida em que não são sujeitos, também não são, na interminável análise,

\footnotetext{
6 "incorporates subjects normatively defined as black, the relations among blacks, whites, and others, and the practices that produce racial difference. Blackness marks a social relationship of dominance and abjection and potentially one of redress and emancipation." (HARTMAN, 1997, p. 56-57)

"racial categorization of the self and the other as the enunciation of a social contract of sorts, an invitation to or provocation of a host of behaviors and expectations that grant one access to society as a member of a privileged or problematized group." (CATANESE, 2011, p. 19)

8 "[p] olitical phenomena are governed by discursive opposition" (GORDON, 2008, p. 87)
} 
"ligados à morte", como diria Abdul JanMohamed (2005). . (MOTEN, 2013, p. 739)

A disputa pela palavra no teatro negro é, então, um ato político que é atuado pelos politicamente mortos. Isso não significa que negros e negras não tenham produzido atos políticos. Assim fizeram em todos os momentos da história. Contudo, quero enfatizar que a construção ideológica de negros e negras como "impensáveis" (TROUILLOT, 1995, p. 73) enquanto sujeitos políticos - do mesmo modo que os sujeitos políticos da Revolução Haitiana eram impensáveis e, por consequência, silenciados pelas narrativas históricas dominantes (TROUILLOT, 1995, p. 73; BUCK-MORSS, 2000, p. $845)$ - tem sustentado a sujeição de negros e negras à violência. Como argumentado por Ana Flauzina e Felipe Freitas,

Uma das maiores sonegações do racismo é o confisco da palavra. A demanda social pelo vilipêndio dos corpos materializada em tortura, encarceramento e morte só se sustenta pela interdição de se verbalizar a dor, de se denunciar as violências, de se politizar o sofrimento. $\mathrm{O}$ abafamento das vozes negras, em última instância, tem garantido a naturalização do terror racial, vendido o extermínio como necessidade e projetado o genocídio como consenso blindado a qualquer questionamento consequente. (FLAUZINA; FREITAS, 2015, p. 7)

Nesse sentido, o não reconhecimento da perspectiva de negros e negras - e consequente supressão da palavra e exclusão do domínio da fala - tanto sustenta como é sustentada pela sujeição de corpos negros à violência contínua e gratuita.

Se tal não reconhecimento e consequente exclusão transforma negros e negras em politicamente mortos e mortas, então o investimento negro na conquista para palavra com vistas à formulação de discursos políticos é tanto ló- gica quanto contraditória. É lógica na medida em que a conquista da palavra e a formulação e enunciação do discurso são parte da estratégia de reconhecimento social da subjetividade política negra. Contudo, tal recurso é contraditório uma vez que implica o exercício político por parte de quem é considerado politicamente morto. A abordagem fenomenológico-existencialista de Gordon em relação ao racismo antinegro (1999) e em sua abordagem fenomenológica do conceito de Consciência Negra de Steve Biko (2002) pode jogar alguma luz sobre esse aparente enigma. De acordo com Gordon, é importante observar que a ideia de consciência negra ${ }^{10}$ só faz sentido se considerada em sua dimensão reflexiva, quer dizer, quando se considera a perspectiva de alguém no mundo e em relação a outras perspectivas (1999, p. 131; p. 132-133). Portanto, uma consciência negra faz sentido na medida em que corresponde ao "conhecimento de cada consciência" numa dada sociedade (GORDON, 1999, p. 131). Contudo, é também necessário considerar que a afirmação de uma Consciência Negra "também levanta questões sobre seres humanos negros, o que é uma contradição em termos em tais sociedades [antinegras]" (GORDON 2008, p. 90), na medida em que negros e negras não têm sua perspectiva socialmente reconhecida.

De certa forma, a afirmação de uma consciência negra, no sentido da afirmação da perspectiva de negros e negras, e a potencial participação no campo da política, constitui um ato político. Gordon adota uma noção clássica de política para discutir a contradição implícita na ideia de que consciência negra exige ação política de quem está excluído da política. Aqui, política pertence a quem pertence à polis, ou seja, quem vive no espaço cercado pelos muros da cidade são aqueles e aquelas habilitados a participar na política, em contraste com quem está excluído, fora dos muros da cidade e que, sendo considerados uma ameaça, precisam ser

\footnotetext{
9 "Black life is lived in political death or that it is lived, if you will, in the burial ground of the subject by those who, insofar as they are not subjects, are also not, in the interminable (as opposed to the last) analysis, "death-bound," as Abdul JanMohamed (2005) would say." (MOTEN, 2013, p. 739)

${ }^{10}$ Aqui eu uso maiúscula para me referir ao conceito de Consciência Negra proposto por Steve Biko (2002) e minúscula para me referir à ideia de consciência negra debatida por Gordon (2008) com base em Frantz Fanon.
} 
violentamente combatidos (GORDON, 2008, p. 87-88). Sendo assim,

O que deveriam fazer quem vive na cidade, mas está estruturalmente fora dela se não aceitar seu lugar de ser alguém de dentro que foi empurrado para fora? Suas questões trazem a possibilidade da política por questão de estabelecer a vida política. É uma atividade paradoxal. Devem fazer política para estabelecer a política onde a política é reconhecida de acordo com normas que sempre os/as tratarão como ilegítimos e ilegítimas - como violentos e violentas - por tentarem modificar o que já está reconhecido como sendo os limites discursivos ${ }^{11}$ (GORDON, 2008, p. 8788)

Não é exagero dizer, então, que a articulação discursiva da perspectiva negra é percebida como inerentemente ameaçadora, demandando, portanto, violenta repressão. Ao mesmo tempo, ao ser percebido como inerentemente violenta, a articulação do discurso a partir da perspectiva negra pode também fazer uso da violência, ou fazer referências à violência, como ingrediente da ação política, opositora, negra.

A percepção da enunciação discursiva da perspectiva negra como algo inerentemente violento fica evidente, por exemplo, na crítica de autoria de Bárbara Heliodora (1923-2015) sobre espetáculo $A$ roda do mundo, intitulada "Contestação no universo do negro” (2001). A crítica inicia afirmando que "Há algumas décadas que o teatro não apresenta contestação tão violenta quanto a que aparece no espetáculo "A roda do mundo", da Cia. dos Comuns" (HELIODORA, 2001, p. 3). Os títulos das subseções, "Ataque ao racismo e à cultura ocidental" e "Tom excessivamente gratuito é desnecessário" levam quem lê a crítica a pensar sobre $A$ roda do mundo como um espetáculo violento. Mais, os títulos tanto da crítica quanto das suas seções deixam implícito que o grupo atuava violentamente no palco na expressão de aspectos da experiência vivida ne- gra, mas mal considera a violência a que negros e negras são submetidos na sociedade brasileira. Dizer que o tom da peça é "excessivamente agressivo" e "desnecessário" é quase o mesmo que acusar negros e negras de serem gratuitamente violentos, em vez de considerar que a afirmação da perspectiva negra no espetáculo visa contestar a violência a que negros e negras são contínua e gratuitamente submetidos e submetidas. Não quero aqui dizer que o espetáculo não estabeleceu em cena, de diversas maneiras, uma relação com a violência. De fato, o grupo não fugiu à possibilidade de se utilizar da violência em seu processo de reivindicação da palavra e da fala para a articulação de um discurso político calcado na perspectiva negra. Contudo, como argumenta Maria Andrea Santos Soares, a crítica de Heliodora prefere enfatizar sua percepção de agressividade no conteúdo ou na emissão das falas, mais do que considerar que tais falas e entonações são "politicamente situadas e de chamados enérgicos à ação" (SOARES, 2016, p. 208). Portanto, como se verá, se assume na peça que tal processo de enunciação a partir da perspectiva negra é violento justamente pelo não reconhecimento social da perspectiva negra. Apesar de ser percebido como violento - e, por vezes, recorrendo à violência - tal processo é colocado no espetáculo como necessário para romper com um processo cíclico e ininterrupto de violência contra o corpo negro.

\section{Da violência no discurso}

Cia dos Comuns estreou sua primeira peça teatral, A roda do mundo em 2001, no Espaço Cabaré da Fundição Progresso, no Rio de Janeiro. A roda do mundo emprega referências aos movimentos e história da capoeira para falar das estratégias de sobrevivência historicamente empregadas por negros e negras no Brasil e na diáspora negra. O texto da peça - assinado pelo diretor do espetáculo, Márcio Meirelles, com a colaboração de Débora Almeida e Gustavo Melo

\footnotetext{
11 " $[w]$ hat should those who live in the city but are structurally outside of it do if they do not accept their place of being insiders who have been pushed outside? Their questions pose the possibility of politics for the sake of establishing political life. It is an activity that is paradoxical. They must do politics in order to establish politics, where politics is recognized according to norms that will always respond to them as illegitimate-as violent—by attempting to change what is already recognized as the discursive limits" (GORDON, 2008, p. 87-88)
} 
- resultou de um processo colaborativo guiado por Meirelles e centrado nas improvisações de cenas feitas pelo elenco. A roda apresenta diversas situações vividas por pessoas negras comuns em sua luta diária por sobrevivência em um fictício bairro negro que poderia estar localizado na cidade do Rio de Janeiro ou em sua área metropolitana. Na peça, sete personagens masculinas e seis personagens femininas foram criadas em referência a situações que aludiam ao que o grupo acreditava serem alguns dos problemas políticos e sociais presentes em favelas e/ ou bairros pobres do Rio de Janeiro e cidades da Baixada Fluminense, majoritariamente populadas por pessoas negras. Dentre os personagens e situações criadas na peça estão, por exemplo, o herbalista que ganha seus sustento vendendo folhas sagradas numa feira de rua enquanto sua filha secretamente negocia sua participação no tráfico de drogas para fugir da pobreza que se abate sobre sua família por gerações; uma empregada doméstica que encara o assédio sexual e corrupção por policiais militares no trajeto entre sua residência e a casa onde trabalha, numa área rica do Rio de Janeiro; uma mulher jovem que participa do tráfico de drogas para escapar de um cenário/roteiro que encurrala algumas mulheres jovens negras daquela comunidade, como gravidez precoce e sujeição à violência ou abandono por parte de seus parceiros, dentre outras. $\mathrm{Na}$ encenação, além das referências à capoeira, a peça também utiliza elementos de outras expressões culturais negras como candomblé, hip hop e samba, junto à música executada ao vivo por um percussionista e um DJ e trilhas de áudio e vídeo. A Cia dos Comuns apresentou A roda do mundo no Espaço Cabaré da Fundição Progresso (2001) e no Teatro Carlos Gomes, no Rio de Janeiro (2002), e no Teatro Vila Velha, em Salvador (2004).

Em $A$ roda do mundo, a Comuns se refere de modo recorrente à reconstituição da palavra para abordar temas filosóficos, sociais, culturais e estéticos a partir da perspectiva negra, seja por temas que imediatamente afetam negros e negras (como a sujeição de negros e negras à violência estatal) ou em referência a debates macro-políticos (tais como o argumento trazido no espetáculo de que a centralidade política e econômica de países europeus e dos Estados Unidos tem gerado violência retributiva de caráter extremista, como o atentado do 11 de setembro). Nesses casos, a referência à violência não é feita apenas como algo que vitimiza negros e negras, mas também como um recurso que pode ser acessado, seja para fazer reconhecer ou como reação ao não reconhecimento de sua perspectiva.

Por exemplo, na primeira cena do espetáculo, o Griot, personagem interpretado por Hilton Cobra, reclama a reconstituição da palavra para produzir uma fala situada na experiência e história vivida de negros e negras:

Imploro-te, Exu, plantares na minha boca o teu axé verbal, restitutindo-me a língua que era minha e me roubaram. É recebendo o axé por ti plantado em mim que posso reconstituir a palavra; é absorvendo esse axé que retomarei o conhecimento de um saber que me foi retirado pela violência, pelo terror e pelo crime daqueles que escravizaram meus ancestrais e hoje me exploram, me discriminam e afirmam sua superioridade e civilização. Quero retomar o meu falar antigo para não me perder nas abstrações vazias, para que meus pés não sejam arrancados de onde devo pisar. Com teu axé percorrerei as distâncias do nosso aiyê feito de terra incerta e perigosa. Nada do que vai ser dito aqui será novo ou surpreendente. Mas tudo que será dito é o que [ainda] nos sufoca. (MEIRELLES et al., 2001, p. 6)

De acordo com o Griot, é a reconstituição da palavra ancorada na história e experiência vivida negras, em oposição às "abstrações vazias”, que irão permitir ao Griot andar pelo mundo enfrentando suas incertezas e perigos. Ao dizer que "nada do que será dito aqui será novo ou surpreendente. Mas tudo que será dito é o que ainda nos sufoca”, o Griot estabelece que os aspectos da experiência vivida negra que serão atuados no palco representam problemas que negros e negras vêm enfrentando por toda sua história e trajetória na diáspora.

Em outra cena, as personagens Aurora (Patrícia Costa) e Centeonze (Gustavo Melo) demonstram a condição de silenciamento imposto a negros e negras ao representar como uma fictícia mulher negra se sente quanto a ser 
negra e pobre.

Aurora - (...) Seu Centeonze, vou te confessar uma coisa. E é uma coisa que tenho horror e tristeza. É porque além de pobre, eu sou preta. Deus não foi nem um pouco justo comigo. A gente sofre muita humilhação e ainda tem que ficar de bico calado. (...) Eu queria ser loira, ia fazer o maior sucesso, né? (...) O senhor não tem uma erva pra ficar branca, não? (MEIRELLES et al., 2001, p. 11)

Aurora diz que negros e negras são constantemente sujeitos a violência e devem, quanto a isso, se calar, se abster da fala para sobreviver apesar da violência a que são submetidos cotidianamente. A solução, segundo ela, é tornar-se branca.

Noutro momento do espetáculo - num discurso é feito diretamente ao público enquanto ele mesmo, não enquanto uma personagem fictícia - Cobra grita a revolta contra a condição negra de sujeição à violência, acompanhado por uma música eletrônica ao fundo e um vídeo mostrando imagens de diferentes revoltas pelo mundo, incluindo fragmentos do atentado ao World Trade Center em Nova Iorque, Estados Unidos, em 2001.

Cobra - (...) respondemos desde sempre/ com a rebeldia dos revoltados/com o ódio que a opressão/e a intolerância são capazes/ de gerar nos homens e mulheres de coragem./ Hoje/o horror agachado como um animal imundo/lançou pelos ares/milhares de corpos indefesos/numa das mensagens mais/contundentes e absurdas/de como a intransigência pode/ser respondida com ódio e igual intransigência/por parte dos humilhados (...) mas dos povos que tiveram que /aprender com a escassez e a fome/talvez parta a saída/se um outro discurso for ouvido antes/para se criar formas/diferentes do discurso do terror/de se combater a supremacia ocidental/a opressão as desigualdades. (MEIRELLES et al., 2001, p. 14-15)

A fala é pontuada por uma contagem regressiva que marca cada um dos cinco minutos da cena, como o cronômetro de uma bomba-relógio. Nessa cena, as imagens do atentado do 11 de setembro são trazidas como a compor o argumento de que dar atenção, escuta e visibilida- de ao discurso dos povos que são violentamente oprimidos por uma supremacia euro-estadunidense é a única maneira de sair do caminho de uma violência retributiva cíclica.

$\mathrm{Na}$ penúltima cena do espetáculo, a personagem Garoto (Vinícius Fonseca) é questionada por Verônica (Débora Almeida), sob a mira de uma arma, sobre sua presença suspeita. Por toda a peça, Garoto anda perto da margem do círculo de madeira que delimita a área de performance do espetáculo, sem dizer uma única palavra, apenas observando tudo que se desenrola na peça. Garoto responde à pergunta de Verônica parte através do alto-falante (tanto a pergunta de Verônica quanto sua resposta foram previamente gravadas, logo, o ator e a atriz não falam nesse momento) e parte através da frase que é projetada no telão, onde se lê: EU QUERO FAZER/MEU PRÓPRIO/FUTURO.

Um círculo discursivo é então fechado na peça, onde um adolescente negro demanda ser dono de seu próprio futuro, algo que depende, de acordo com o Griot do início da peça, de sua habilidade de reconstituir sua palavra no presente, situada em relação a sua história passada e à sua experiência no presente.

\section{Breves considerações e ressalvas finais}

$\mathrm{O}$ engajamento negro com a palavra, uma vez associado ao esforço por fazer reconhecer a perspectiva negra, carrega "um implícito ataque ao racismo branco"12 (MORE, 2008, p. 55-56). Contudo, o engajamento da Cia dos Comuns na recuperação da palavra e da fala ainda demandam duas breves considerações: primeiro, a perspectiva negra nas peças da Comuns é articulada de forma teatral e, portanto, não carregam necessariamente o grau de coerência que é esperado de um discurso político no sentido estrito do termo. Dessa forma, há uma série de contradições que são expostas na peça, e muitas vezes nos discursos das personagens, que vão em sentido contrário ao projeto político do grupo. Isso é feito propositalmente, no sentido de provocar no público reações às situações apresentadas em cena, em vez de entregar ao público uma receita de como agir em face dessa ou daquela situação política e social. Segundo, é importante salientar que o engaja- 
mento da Comuns com a palavra não significa que o grupo abriu mão do corpo, e mais especificamente do corpo negro, como um meio fundamental de expressar a perspectiva negra no mundo. De fato, o grupo não demanda a palavra de modo a assumir uma hierarquia da palavra como expressão da razão e do corpo como expressão da natureza. O corpo negro é assumido no teatro negro da Cia dos Comuns, como de resto em boa parte dos teatros negros, como potente locus da memória (MARTINS, 1995; NARANJO, 2004). Assim, o discurso produzido pela Cia dos Comuns, é articulado tanto verbalmente quanto corporalmente.

12 "an implicit attack on white racism" (MORE, 2008, p. 55-56) 


\section{REFERÊNCIAS}

BIKO, Steve; STUBBS, Alred. I Write What I Like: Selected Writings/Edited with a Personal Memoir by Aelred Stubbs; Preface by Archbishop Desmond Tutu; Introduction by Malusi and Thoko Mpumlwana; with a New Foreword by Lewis R. Gordon. [s.l.]. Chicago: University of Chicago Press, 2002. 219 p.

BUCK-MORSS, Susan. Hegel and Haiti. Critical Inquiry, [s.l.], v. 26, n. 4, p. 821865, jul. 2000. Disponível em: <http://www.jstor.org/stable/1344332>. Acesso em: 27 out. 2012

CATANESE, Brandi Wilkins. The Problem of the Color[Blind]: Racial Transgresssion and the Politics of Black Performance. 1 ed. Ann Arbor: The University of Michigan Press, 2011. 214p.

DEUS, Zélia Amador de. Política e Cultura: Africanidades Paraenses. Texto publicado em documento impresso do III Fórum Nacional de Performance Negra. Salvador, 2009. p. 183-196.

FANON, Frantz. Black Skin, White Masks. New York: Grove Press; Berkeley: Publishers Group West, 2008. 206 p.

FLAUZINA, Ana Luiza Pinheiro; FREITAS, Felipe da Silva. Enunciando Dores, Assinando Resistência. In: FLAUZINA, Ana Luiza Pinheiro et al. (org.). Discursos Negros: Legislação Penal, Política Criminal e Racismo. Brasília: Brado Negro, 2015. p. 7-11.

GORDON, Lewis. Bad Faith and Antiblack Racism. Armherst.: Humanity Books, 1999. $222 \mathrm{p}$.

A Phenomenology of Biko's Black Consiousness. In: MNGXITAMA, Andile; ALEXANDER, Amanda; GIBSON, Nigel C. Biko Lives: Contesting the Legacies of Steve Biko. 1 ed. New York: Palgrave Mcmillan, 2008. p. 83-93.

HARTMAN, Saidiya V. Scenes of Subjection: Terror, Slavery, and Self-Making in Nineteenth-Century America. New York: Oxford University Press, 1997. 281 p.

HELIODORA, Bárbara. Contestação no universo do negro. O Globo. Rio de Janeiro, 30 nov. 2001. Segundo Caderno, p. 3.

LIMA, Evani Tavares. Um olhar sobre o teatro negro do Teatro Experimental do 


\section{REFERÊNCIAS}

Negro e do Bando de Teatro Olodum. 2010. 345 f. Tese (Doutorado em Artes) Instituto de Artes, Universidade Estadual de Campinas, Campinas, 25 fev. 2010.

MARTINS, Leda Maria. A cena em sombras. Coleção Debates, n. 267. São Paulo: Perspectiva, 1995. 217p.

MEIRELLES, Marcio; ALMEIDA; Débora; MELO, Gustavo e elenco da Cia dos Comuns. A Roda do Mundo. Cia dos Comuns. Rio de Janeiro, 2001. Texto impresso, não publicado, constante do programa do espetáculo A roda do mundo.

MOTEN, Fred. Blackness and Nothingness (Mysticism in the Flesh). South Atlantic Quarterly, [s. 1.], v. 112, n. 4, p. 737-780, outono, 2013. Disponível em: $<$ https://doi.org/10.1215/00382876-2345261>. Acesso em: 5 jul. 2019.

MORE, Mabogo P. Biko: Africana Existentialist Philosopher. In: MNGXITAMA, Andile; ALEXANDER, Amanda; GIBSON, Nigel C. Biko Lives: Contesting the Legacies of Steve Biko. 1 ed. New York: Palgrave Mcmillan, 2008. p. 45-68.

NARANJO, Julio Moracén. O Teatro Negro Caribenho: À Sombra de Si Mesmo. Revista Brasileira do Caribe, v. 5, n. 9, p. 11-151, jul./dez. 2004

SARTRE, Jean-Paul. Being and Nothingness: an Essay on Phenomenological Ontology. New York: Philosophical Library, 1956. 638p.

SOARES, Maria Andrea Santos. Pensamento e ação política no teatro negro da "Companhia dos Comuns". Urdimento - Revista de Estudos em Artes Cênicas, v. 1, n. 26, p. 199-217, jul. 2016. Disponível em: <https://doi.org/10.5965/1414573 101262016199>. Acesso em: 4 ago. 2017.

TROUILLOT, Michel-Rolph. Silencing the Past: Power and the Production of History. 1 ed. Boston: Beacon Press, 1995. 195p.

WRIGHT, Michelle M. Becoming Black: Creating Identity in the African Diaspora. 1 ed. North Carolina: Duke University Press, 2004. 280p.

WYNTER, Sylvia. Beyond the Word of Man: Glissant and the New Discourse of the Antilles. World Literature Today, [s.1.], v. 63, n. 4, p. 637-648, outono, 1989. Disponível em: <https://doi.org/10.2307/40145557>. Acesso em: 10 jul. 2019. 


\begin{abstract}
In this essay I analyze the relationship between discourse and violence in teatro negro based on the play $A$ roda do mundo, by Cia dos Comuns. I argue that by reclaiming the word, Cia dos Comuns confronts one of the main aspects related to the persistent objectification and dehumanization of the black body: the denial of recogntion of the black body as a body able to have and exercise a proper perspective about itself and about the surrounding world.
\end{abstract}

\title{
Keywords
}

Black theater. Violence. Black body

Recebido em: 04 abr. 2020

Aprovado em: 15 jun. 2020

Publicado em: 13 ago. 2020 